\title{
HUBUNGAN PENGETAHUAN DENGAN UPAYA PENCEGAHAN DINI OSTEOPOROSIS WANITA USIA 45-60 TAHUN
}

\author{
Melva Manurung, Dosmaida Nababan, Pretty Situmorang \\ STIKes Arjuna Prodi D3 Keperawatan \\ Email:melva_manroe84@yahoo.com; fretysitumorang@gmai.com
}

\begin{abstract}
International Osteoporosis Foundation (IOF) revealed that 1 in 4 women in Indonesia with an age of 50-80 years have a risk of osteoporosis. Loss of the hormone estrogen after menopause increases risk of developing osteoporosis. This research aims to reveal the Relationship between Knowledge and Early Prevention of Osteoporosis in Women 4560 Years Old in Banua Huta Village, Sigumpar District, Toba Samosir Regency in 2020. This study used a descriptive approach with a sample of 35 people used total sampling. This study uses the Spearman correlation test. The results of the study are related to knowledge with early prevention of osteoporosis Women aged 45-60 years in Banua Huta Village, both variables with a sig. (2-tailed) value of 0.003 with a very strong relationship strength $r=0.09$. This happens because people's perceptions about the concept of healthy pain that are not in line even very contrary to the health service provider, the community consider illness is a state of the body lying in bed and can not do any activities so prevention efforts are ignored because health problems are not a priority in life and life and there are still many factors that influence a person to take any action not just knowledge. Health workers in Puskesmas have the role of providing information in the form of counseling or health education to elderly women about knowledge and efforts to prevent early osteoporosis so that the number of osteoporosis does not increase.
\end{abstract}

Keywords: osteoporosis, knowledge, early prevention

\section{PENDAHULUAN}

Osteoporosis merupakan masalah kesehatan fisik yang menjadi perhatian dan harus diwaspadai pada wanita yang mengalami menopause. Osteoporosis sering disebut silent epidemic diseases, dapat menyerang secara diam-diam, tanpa menimbulkan tanda-tanda khusus, sampai pasien dapat mengalami keadaan patah tulang (Misnadiarly, 2013).

Penyebab penyakit osteoporosis yaitu rendahnya kandungan hormon estrogen pada wanita, dan kurangnya aktivitas fisik, kurang terkena sinar matahari, kekurangan konsumsi vitamin $\mathrm{D}$, usia yang sudah lanjut dan rendahnya asupan kalsium. Hal ini dibuktikan dengan rendahnya konsumsi kalsium rata-rata masyarakat Indonesia sebesar $254 \mathrm{mg}$ per hari, dan hanya seperempat dari standar internasional untuk orang dewasa, yaitu 1000-1200 mg per hari (Tjahjadi, 2017).

Jumlah wanita usia 50 tahun ke atas diperkirakan meningkat pada saat ini dari 500 juta menjadi lebih dari 1 miliar pada 2030, sedangkan wanita premenopause sebanyak 342 juta. Setiap tahun sekitar 25 juta wanita di seluruh dunia diperkirakan mengalami 
menopause. Jumlah wanita yang berusia tua diperkirakan tahun 2025 di Asia akan melonjak dari 107 juta ke 373 juta. Risiko osteoporosis pada wanita menjadi 4 kali lebih tinggi di Indonesia dan osteoporosis menduduki peringkat kedua, di bawah penyakit jantung sebagai masalah kesehatan utama dunia (Sefrina, 2016).

Menurut data Internasional Osteoporosis Foundation (IOF) lebih dari $30 \%$ wanita diseluruh dunia mengalami resiko patah tulang akibat osteoporosis, bahkan mendekati $40 \%$. Penderita osteoporosis di Eropa, Jepang, dan Amerika adalah sebanyak 75 juta penduduk, sedangkan di Cina 84 juta penduduk, dan penderita osteoporosis di seluruh dunia sebanyak 200 juta (Mithal, Ebeling, \& Kyer, 2013).

Dampak terjadinya osteoporosis telah mencapai tingkat yang patut diwaspadai, 1 dari 3 wanita dan 1 dari 5 pria di Indonesia terserang osteoporosis atau keretakan tulang, yaitu mencapai $19,7 \%$ dari populasi di Indonesia. Prevalensi kejadian di Indonesia untuk umur kurang dari 70 tahun pada wanita sebanyak 18-30\%. (Riskesdas, 2013). Kejadian patah tulang (fraktur) akibat osteoporosis mencapai 1,7 juta orang di seluruh dunia dan diperkirakan angka ini akan terus mengalami peningkatan sampai 6,3 juta orang pada tahun 2050 (Kementerian Kesehatan RI, 2015).
Penanganan osteoporosis dianggap sulit dan memerlukan praktik pencegahan melalui gaya hidup yang sehat (Hardayati, 2013). Trend gaya hidup yang dimaksud seperti kebiasaan merokok, keinginan menjaga tubuh tetap langsing, meminum alkohol, kurang melakukan aktivitas, jarang melakukan kegiatan olahraga, kurang terpapar sinar matahari, usia makin bertambah, kurang mendapatkan asupan kalsium dan vitamin D (Stetzer, 2011).

Sejumlah Provinsi dengan resiko tertinggi osteoporosis adalah Sumatera Selatan 27,7\%, Jawa Tengah 24,02\%, DI Yogyakarta 23,5\%, Sumatera Utara $22,82 \%$, Jawa Timur 21,42\%, dan Kalimantan Timur 10,5\% (Riskesdas, 2013). Tingginya kejadian osteoprosis dapat menimbulkan komplikasi yaitu kejadian patah tulang/fraktur. Insidensi fraktur osteoporosis tulang panggul lebih banyak dialami wanita pada populasi > 55 tahun dan kasus fraktur tertinggi terjadi pada kelompok usia 9599 tahun yaitu sebanyak 1680 kasus fraktur. Sedangkan pada populasi pria, paling banyak terjadi pada rentang usia 90-94 tahun dengan jumlah 718 kasus fraktur (Kementerian Kesehatan RI, 2015).

Sekitar 9 juta fraktur timbul pada osteoporosis, dengan fraktur tersering pada tulang pinggul, pergelangan tangan, vertebra dan humerus (Noor, 
2014). Penanganan fraktur akibat osteoporosis membutuhkan biaya sangat tinggi di Eropa mencapai 450 triliun Rupiah sedangkan di Amerika mencapai 280 triliun Rupiah (Åkesson et al., 2013).

Peran masyarakat sangat penting dalam menangani dan melakukan pencegahan terhadap penyakit osteoporosis dengan berusaha melakukan perubahan gaya hidup yang lebih sehat. Rendahnya kesadaran masyarakat dalam dan banyaknya yang menganggap osteoporosis hanya akan terjadi setelah seseorang menjadi tua. Sedangkan pada lansia yang kurang pengetahuannya tentang penyakit osteoporosis tidak mengetahui dampak dan risiko yang dapat terjadi karena penyakit tersebut.

Berdasarkan studi pendahuluan yang telah dilakukan di Desa Banua Huta Kecamatan Sigumpar Kabupaten Toba Samosir, didapatkan jumlah wanita dengan rentang usia 45-60 tahun sebanyak 142 orang dan hasil wawancara dengan 35 orang banyak yang mengalami tanda dan gejala osteoporosis. Berdasarkan data tersebut, maka penulis tertarik untuk meneliti hubungan pengetahuan dengan upaya pencegahan dini osteoporosis wanita usia 45-60 tahun di Desa Banua Huta Kecamatan Sigumpar Kabupaten Toba Samosir".

\section{METODE}

Penelitian ini menggunakan pendekatan deskriptif. Penelitian ini bertujuan untuk mengetahui hubungan pengetahuan dengan upaya pencegahan dini osteoporosis. Penelitian dilakukan pada bulan Januari 2020. Populasi adalah wanita usia 45-60 Tahun di Desa Banua Huta Kecamatan Sigumpar Kabupaten Toba Samosir dengan menggunakan total sampling, dan sampel sebanyak 35 orang.

Pengumpulan data dilakukan dengan memberikan kuesioner pengetahuan sebanyak 15 pernyataan dan kuesioner upaya pencegahan sebanyak 10 pernyataan. Analisa data menggunakan uji korelasi Spearmen.

\section{HASIL DAN PEMBAHASAN}

Hasil

Tabel 1. Distribus

Frekuensi Responden Berdasarkan Usia

\begin{tabular}{ccrc}
\hline \multirow{2}{*}{ No } & \multirow{2}{*}{ Usia } & \multicolumn{2}{c}{ Jumlah } \\
\cline { 3 - 4 } & & $\boldsymbol{f}$ & \% \\
\hline 1 & $45-50$ & 12 & 34,2 \\
2 & $51-55$ & 17 & 48,5 \\
3 & $56-60$ & 6 & 13,3 \\
\hline & Jumlah & 35 & 100,0 \\
\hline
\end{tabular}

Hasil penelitian pada Tabel 1 menunjukkan dari 35 diketahui 12 responden $(34.2 \%)$ berusia diantara 45 50 tahun, 17 responden (48.5\%) berusia 51-55 tahun dan 6 responden (13.3\%) berusia 56-60 tahun. Dapat disimpulkan bahwa sebagian besar responden 17 
responden (48.5\%) adalah ibu berusia 51-56 tahun.

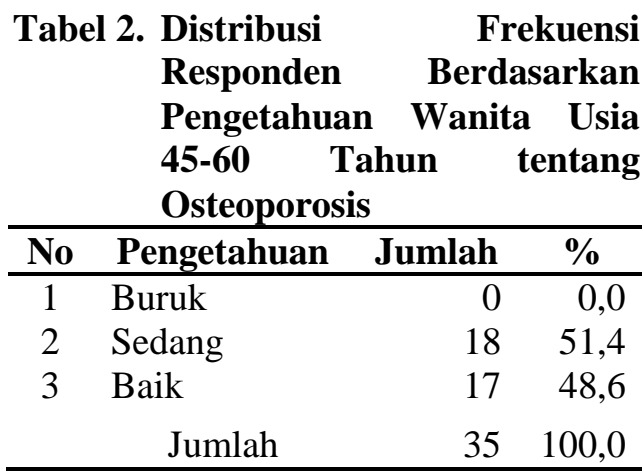

Hasil penelitian pada Tabel 2 menunjukkan dari 35 responden wanita usia 45-60 tahun didapat 18 responden (51.4\%) berpengetahuan sedang tentang osteoporosis dan 17 responden (48.6\%) berpengetahuan baik tentang osteoporosis.

\begin{tabular}{|c|c|c|c|}
\hline \multicolumn{3}{|c|}{ Tabel 3. Distribusi } & $\begin{array}{l}\text { kuens } \\
\text { sarkar }\end{array}$ \\
\hline & Upaya & Pencegahan & \\
\hline & $\begin{array}{l}\text { Osteoporo } \\
\text { 45-60 Tah }\end{array}$ & Wanita & \\
\hline No & Pengetahuan & Jumlah & $\%$ \\
\hline 1 & Buruk & 0 & 0 \\
\hline 2 & Sedang & 10 & 28 , \\
\hline 3 & Baik & 25 & 71 , \\
\hline & Jumlah & 35 & $100, \mathrm{C}$ \\
\hline
\end{tabular}

Hasil penelitian pada Tabel 3 menunjukkan dari 35 responden wanita usia 45-60 tahun tentang upaya pencegahan dini osteoporosis wanita usia 45-60 tahun, 10 responden $(28,6 \%)$ berpengetahuan sedang tentang Upaya pencegahan dini osteoporosis dan 25 responden $(71,4 \%)$ berpengetahuan baik tentang Upaya pencegahan dini osteoporosis.
Dapat disimpulkan bahwa sebagian besar sebanyak 25 responden (71.4\%) mendapatkan berpengetahuan baik dalam upaya pencegahan dini osteoporosis.

Hubungan Pengetahuan Wanita usia 45-60 tahun dengan Upaya Pencegahan Dini Osteoporosis

Tabel 4. Hasil Uji Korelasi

\begin{tabular}{|c|c|c|c|c|}
\hline \multirow{5}{*}{$\begin{array}{l}\text { Spear } \\
\text { man's } \\
\text { rho }\end{array}$} & tot & $\begin{array}{l}\text { Correlation } \\
\text { Coefficient }\end{array}$ & $\begin{array}{c}\text { Tot } \\
1.000\end{array}$ & $\begin{array}{r}\text { Total } \\
.099\end{array}$ \\
\hline & & Sig. (2-tailed) & & .003 \\
\hline & & $\mathrm{N}$ & 35 & 35 \\
\hline & total & $\begin{array}{l}\text { Correlation } \\
\text { Coefficient } \\
\text { Sig (2-tailed) }\end{array}$ & .099 & 1.000 \\
\hline & & $\mathrm{N}$ & 35 & 35 \\
\hline
\end{tabular}

Berdasarkan Tabel 4 di atas menunjukkan angka sig.(2-tailed) adalah 0,003 berarti terdapat hubungan pengetahuan dengan upaya pencegahan dini osteoporosis wanita usia 45-60 tahun, dengan nilai koefisien korelasi $r=$ 0.099 yang berarti pengetahuan dengan upaya pencegahan dini osteoporosis memiliki hubungan yang sangat kuat (kekuatan hubungan sangat kuat).

\section{Pembahasan}

Tingkat pengetahuan sangat mempengaruhi sikap dan perilaku setiap individu untuk menjaga pola hidup yang baik dengan memperhatikan pola makan sehat dan olahraga secara teratur, dan konsumsi kalsium yang cukup untuk kebutuhan tubuh. Pengetahuan lansia tentang osteoporosis dapat diperoleh 
melalui media elektronik, iklan maupun penyuluhan, beberapa penelitian menunjukkan $37.5 \%$ diperoleh melalui media elektronik (Hardayati, 2013). Berdasarkan data diperoleh $51.4 \%$ berpengetahuan sedang tentang osteoporosis dan $48.6 \%$ berpengetahuan baik tentang osteoporosis. Pengetahuan tentang osteoporosis berpengaruh terhadap angka kejadian osteoporosis. Menurut Kementerian Kesehatan RI, (2015) pencegahan osteoporosis dapat dilakukan dengan meningkatkan pengetahuan terhadap masyarakat mengenai faktor risiko dan penyebab osteoporosis.

Penelitian Rajaratenam, Martini, dan Lipoeto (2014) yang dilakukan di Kelurahan Jati menunjukkan sebagian besar wanita usila memiliki tingkat pengetahuan osteoporosis yang baik dan ditemukan tingkat pengetahuan kurang. Peneliti berasumsi pengetahuan lansia baik karena mendapat banyak informasi dari berbagai tempat. Menurut Notoatmodjo (2012), pengetahuan merupakan bagian kekayaan mental yang secara langsung atau tidak langsung dapat memperkaya kehidupan seseorang. Setiap pengetahuan memiliki ciri-ciri yang spesifik mengenai apa (ontologi), bagaimana (epistologi) dan untuk apa (aksiologi). Pengetahuan yang dimiliki seseorang mempengaruhi perilakunya, semakin baik pengetahuan seseorang maka perilakunya pun semakin baik.

Berdasarkan hasil penelitian menunjukkan tentang upaya pencegahan dini osteoporosis wanita usia 45-60 tahun, sebanyak $28.6 \%$ berpengetahuan sedang dan $71.4 \%$ berpengetahuan baik. Penelitian Wardhana, Nugroho, dan Hapsari, (2012) menyebutkan setiap 1 dari 3 wanita usia 50 tahun memiliki kecenderungan terkena osteoporosis ataupun terdapat kemungkinan yang terjadi sebanyak 67\%. Osteoporosis hanya dapat dicegah atau ditunda kejadiannya, namun bila kurang pengetahuan dan pencegahannya tentang osteoporosis maka kejadian osteoporosis cenderung meningkat.

Hasil penelitian menunjukkan adanya hubungan pengetahuan dengan upaya pencegahan dini Osteoporosis Wanita usia 45-60 tahun. Penelitian sejalan dengan Setiani, Setyaningsih, dan Fungky (2015) sebagian besar wanita pra menopause memiliki tingkat pengetahuan yang tinggi tentang osteoporosis, mayoritas wanita pramenopause memiliki perilaku yang kurang aktif dalam pencegahan osteoporosis. Penelitian ini mendapatkan ada hubungan tingkat pengetahuan tentang osteoporosis dengan perilaku pencegahan osteoporosis pada wanita pra-menopause. 
Sesuai dengan hasil wawancara dengan beberapa lansia, mereka menguapayakan agar tidak terkena osteopororosis terlihat dari mereka menjaga jenis makanan, melakukan olahraga 2 atau 3 kali seminggu selama 30 menit, peneliti berasumsi tindakan pencegahan yang dilakukan oleh lansia terhadap pencegahan osteoporosis baik karena mereka mengerti tentang osteopororosis. Lansia menyadari upaya mencegah lebih baik dari pada mengobat dan didukung oleh tenaga kesehatan yang aktif memberikan penyuluhan-penyuluhan/pendidikan kesehatan.

\section{KESIMPULAN DAN SARAN}

Hasil penelitian menunjukkan sebanyak $51.4 \%$ berpengetahuan sedang dan sebanyak $48.6 \%$, berpengetahuan baik tentang osteoporosis. Sebanyak $71.4 \%$, melakukan upaya pencegahan dini osteoporosis.

Terdapat hubungan pengetahuan dengan upaya pencegahan dini Osteoporosis Wanita usia 45-60 tahun dengan nilai sig.(2-tailed) 0,003 berarti dengan kekuatan hubungan sangat kuat. Saran

Diharapkan kepada pihak pelayanan keperawatan agar selalu memotivasi lansia untuk mencegah terjadinya osteoporosis dan lebih menekankan pemberian informasi berupa penyuluhan/pendidikan kepada wanita usia tua tentang pengetahuan dan upaya pencegahan dini osteoporosis agar angka lansia sehat semakin meningkat.

Mengingat tidak semua sampel melakukan pencegahan osteoporosis secara aktif, diharapkan masyarakat dapat secara aktif meningkatkan upaya pencegahan osteoporosis.

\section{DAFTAR PUSTAKA}

Åkesson, K., Marsh, D., Mitchell, P. J., McLellan, A. R., Stenmark, J., Pierroz, D. D., ... Cooper, C. (2013). Capture the Fracture: A best practice framework and global campaign to break the fragility fracture cycle. Osteoporosis International. https://doi.org/10.1007/s00198-0132348-Z

Hardayati, Y. A. (2013). Faktor-faktor yang berhubungan dengan perilaku pencegahan osteoporosis pada wanita premenopause di Komplek Kartika Sejahtera Blok J RW.06.

Kementerian Kesehatan RI. (2015). Pusat data dan informasi data dan kondisi penyakit osteoporosis di Indonesia. Jakarta: Departemen Kesehatan.

Misnadiarly. (2013). Osteoporosis: Pengenalan, faktor risiko, pencegahan, dan pengobatan (1st ed.). Jakarta Barat: Akademia Permata.

Mithal, A., Ebeling, P., \& Kyer, C. S. (2013). The Asia-Pacific Regional Audit: Epidemiology, costs \& burden of osteoporosis in 2013. International Osteoporosis Foundation. https://doi.org/10.1002/yd.20044

Noor, Z. (2014). Buku ajar: Osteoporosis patofisiologi dan peran atom mineral dalam manajemen terapi. Jakarta: Salemba Medika.

Notoatmodjo, S. (2012). Promosi 
Kesehatan \& Ilmu Perilaku. In Jakarta: Rineka Cipta.

Rajaratenam, S. G., Martini, R. D., \& Lipoeto, N. I. (2014). Hubungan tingkat pengetahuan dan sikap dengan tindakan pencegahan osteoporosis pada wanita usila di Kelurahan Jati. Jurnal Kesehatan Andalas.

https://doi.org/10.25077/jka.v3i2.96

Riskesdas. (2013). Riset Kesehatan Dasar tahun 2013. Kementerian Kesehatan Republik Indonesia. https://doi.org/10.1517/13543784.7.5 .803

Sefrina, A. (2016). Osteoporosis the silent disease (Maya, ed.). Yogyakarta: Rapha Publishing.

Setiani, D. Y., Setyaningsih, R., \& Fungky, W. Y. (2015). Hubungan tingkat pengetahuan osteoporosis dengan perilaku pencegahan osteoporosis pada wanita pre menopause di Kelurahan Tipes Surakarta. Kosala: Jurnal Ilmu Kesehatan.

https://doi.org/10.37831/jik.v3i2.75

Stetzer, E. S. (2011). Identifying risk factors for osteoporosis in young women. The Internet Journal of Allied Health Sciences and Practice.

Tjahjadi, V. (2017). Mengenal mencegah, mengatasi silent killer osteoporosis. Yogyakarta: Romawi Press.

Wardhana, W., Nugroho, H., \& Hapsari, R. (2012). Faktor - faktor risiko osteoporosis pada pasien dengan usia di atas 50 tahun. Jurnal Kedokteran Diponegoro. 